\title{
ANALISIS PETROFISIKA DAN PERHITUNGAN CADANGAN GAS ALAM LAPANGAN “KAPRASIDA” FORMASI BATURAJA CEKUNGAN SUMATERA SELATAN
}

\author{
M. Iqbal Maulana, Widya Utama, Anik Hilyah \\ Jurusan Teknik Geofisika, FTSP Institut Teknologi Sepuluh Nopember \\ e-mail: widya@geofisika.its.ac.id
}

\begin{abstract}
Abstrak. Analisis petrofisika dilakukan untuk evaluasi parameter petrofisika pada Formasi Baturaja. Identifikasi porositas, kandungan serpih, saturasi air dan permeabilitas dilakukan pada empat sumur. Estimasi kandungan serpih dilakukan dengan menggunakan log Gamma Ray, estimasi porositas efektif dilakukan dengan menggunakan gabungan log densitas dan log neutron, Saturasi air dihitung dengan menggunakan persamaan Indonesia, dan permeabilitas dihitung dengan menggunakan persamaan Timur. Rata-rata nilai kandungan serpih tiap sumur adalah 18,2 \%, 12,55 \%, $20 \%$, dan $40 \%$. Nilai ratarata nilai porositas pada tiap sumur adalah 16,4 \%, 14,6 \%, 15,3\%, 12,7 \%. Rata-rata nilai saturasi air pada tiap sumur adalah $40 \%, 62 \%, 67 \%$, dan $64 \%$. Rata-rata nilai permeabilitas pada tiap sumur adalah $34,65 \mathrm{mD}, 61,15 \mathrm{mD}, 157,3 \mathrm{mD}$. Selanjutnya dilakukan lumping dengan mengggunakan nilai penggal (cut-off) sebagai berikut VShale $\leq 0,7$, PHIE $\geq 8 \%$, SW $\leq 70 \%$, Permeabilitas $\geq 1 \mathrm{mD}$. Cadangan gas alam pada 2 kompartemen reefal diestimasi. Batas atas Volume untuk perhitungan cadangan adalah Peta Top Surface formasi Baturaja. Sedangkan batas bawahnya adalah data kedalaman Gas Water Contact (GWC). Data kedalaman GWC merupakan data perusahaan yang didapatkan dari pressure test dan uji kandung lapisan. Kompartemen utara dilewati oleh sumur MI-1, sedangkan kompartemen selatan dilewati oleh sumur $\mathrm{MI}-2, \mathrm{MI}-3$, dan $\mathrm{MI}-6$. Perhitungan cadangan pada kompartemen utara menggunakan parameter petrofisika hasil analisis pada sumur MI-1. Hasil perhitungan cadangan pada kompartemen Utara adalah sebesar 5 BSCF dan kompartemen Selatan sebesar 6 BSCF.
\end{abstract}

Kata kunci: analisis petrofisika; formasi Baturaja; perhitungan cadangan

\begin{abstract}
This petrophysical analysis is carried out to evaluate petrophysicalparametres of the Baturaja Formation. Porosity, shale volume, water saturation, and permeability were identified from well logs in four wells. Shale volume estimation is done using Gamma Ray log, porosity estimation is done using density log and neutron log. Water saturation is estimated using Indonesian method. Permeability is estimated using Timur Equation. The average of shale volume in four wells are 18,2 \%, 12,55 \%, $20 \%$, dan $40 \%$. The average porosity in each wells are 16,4\%, 14,6\%, 15,3\%, 12,7\%. The average water saturation in each wells are $40 \%, 62 \%, 67 \%, 64 \%$. The average permeability in each wells are 34,65mD, $61,15 \mathrm{mD}, 157,3 \mathrm{mD}, 16,32 \mathrm{mD}$. After that, lumping is done using cut-off values. The cut-off values are VShale $\leq 0,7$, PHIE $\geq 8 \%, S W \leq 70 \%$, Permeability $\geq 1 \mathrm{mD}$. Reserve gas in two reefal compartment is estimated. The Volume top boundary is Top Surface Baturaja Formation Map in Grid 3D. And the bottom boundary is the depth data of Gas Water Contact (GWC). GWC depth data is a decision from the company. GWC is estimated by pressure test and drill stem test. North reefal compartment is passed by well $\mathrm{MI}-1$, and south reefal compartment is passed by well $\mathrm{MI}-2, \mathrm{MI}-3$, and $\mathrm{MI}-6$. The result of reserve estimation in North compartment is 5 BSCF and South compartment is 6 BSCF.
\end{abstract}

Keyword: petrophysical analysis; Baturaja formation; reserve estimation

\section{PENDAHULUAN}

Peran dari metode logging sangatlah penting karena memberikan gambaran detail mengenai sifat fisis dari batuan sekitar lubang pengeboran. Dengan melakukan analisis petrofisika menggunakan data log akan diketahui ketebalan tiap lapisan batuan atau memberikan informasi secara vertikal. Data luar seperti data core (sampel batuan inti dari sumur bor) atau data dari lumpur yang digunakan untuk pengeboran (mudlog) juga dibutuhkan untuk memperkuat analisis. Dengan adanya analisis petrofisika, maka deskripsi mengenai batuan reservoar yang mengandung hidrokarbon serta perhitungan cadangan hidrokarbon yang terkandung di dalamnya akan lebih mudah dilakukan. 
Analisis petrofisika sangat berguna untuk karakterisasi reservoar. Karakterisasi reservoar pada analisis petrofisika dilakukan dengan mempelajari litologi, porositas, saturasi air, dan permeabilitas lapisan batuan di bawah permukaan. Penentuan litologi melalui identifikasi log Gamma Ray bertujuan untuk membedakan lapisan permeabel atau bukan. Log densitas dan log neutron dapat digunakan untuk menghitung porositas lapisan batuan, dan log resistivitas digunakan untuk mencari saturasi air lapisan batuan.

Dengan melakukan analisis petrofisika pada formasi geologi, dapat diketahui struktur bawah permukaan serta zona potensi hidrokarbon dari lapangan produksi. Namun, dalam pengembangan sebuah lapangan, perlu juga diketahui seberapa besar cadangan hidrokarbon yang dapat diperoleh dari lapangan tersebut.

\section{DASAR TEORI}

\section{A. Analisis Petrofisika}

Analisis petrofisika merupakan salah satu proses yang penting dalam usaha untuk mengetahui karakteristik suatu reservoar. Analisis petrofisika diawali oleh perolehan data bawah permukaan melalui proses well logging pada lubang pengeboran.

Untuk melakukan analisis petrofisika diperlukan beberapa parameter penting batuan dalam suatu formasi, di antaranya adalah porositas, satrasi air, shale volume dan permeabilitas.

\section{B. Porositas}

Porositas didefinisikan sebagai perbandingan antara volume batuan yang tidak terisi oleh padatan terhadap volume batuan secara keseluruhan. Log untuk mengukur porositas terutama adalah log densitas, neutron, sonik dan Rxo (Heysse, 1991). Log-log tersebut dapat mengukur parameter tertentu yang kemudian dapat digunakan untuk menghitung porositas. Persamaan untuk menghitung nilai porositas batuan adalah sebagai berikut:

$$
\mathrm{PHIT}=\mathrm{PHIE}+\mathrm{Vsh} \cdot \phi \mathrm{Tsh}
$$

\section{Permeabilitas}

Permeabilitas merupakan besaran yang digunakan untuk menunjukkan seberapa besar kemampuan suatu batuan untuk mengalirkan fluida yang terkandung di dalamnya. Permeabilitas batuan penting untuk dicari guna mengetahui seberapa efektif batuan tersebut untuk diproduksi. Permeabilitas dapat dihitung menggunakan persamaan Timur sebagai berikut :

$$
K=0.136 \times\left[\left(\varnothing \mathrm{e}^{\wedge} 4.4\right) /\left(S_{w i r r}^{\wedge} 2\right)\right]
$$

\section{Saturasi Air}

Saturasi air atau kejenuhan air adalah perbandingan kuantitas (volume) suatu fluida dengan pori-pori batuan tempat fluida tersebut berada. Saturasi merupakan persentase bagian dari suatu pori yang terisi fluida. Karena tidak mungkin ada pori-pori yang kosong oleh fluida (vakum), maka $\mathrm{S} w+\mathrm{So}+\mathrm{Sg}=1$. Secara umum, ada 2 cara untuk menentukan saturasi, yaitu dengan analisis laboratorium atas sampel core dari reservoar, dan dengan log. Dalam penelitian ini, saturasi air dihitung menggunakan persamaan Indonesia sebagai berikut :

$$
\mathrm{Sw}=\left\{\left[\left(\frac{V s h^{2-V s h}}{R s h}\right)^{\frac{1}{2}}+\left(\frac{\mathrm{e}^{m}}{R w}\right)^{\frac{1}{2}}\right]^{2} R t\right\}^{\frac{-1}{n}}
$$

\section{E. Kandungan Serpih (Shale Volume)}

Perhitungan Shale Volume adalah menghitung kandungan serpih dalam batuan reservoar dengan memanfaatkan log Gamma Ray. Oleh karena itu, perhitungan volume serpih dilakukan sebagai koreksi pada porositas total sehingga dapat diperoleh porositas efektif batuan reservoar. Perhitungan volume serpih $\left(V_{\text {sh }}\right)$ dapat dilakukan secara linear berdasarkan Log Gamma Ray, berdasarkan persamaan Index Gamma Ray $\left(I_{\mathrm{GR}}\right)$ :

$$
\begin{aligned}
& \text { VSHgr }=(\text { GRlog }- \text { GRmatrix }) / \\
& \text { (GRshale-GRmatrix) }
\end{aligned}
$$




\section{F. PerhitunganCadangan}

Metode perhitungan volumetrik berdasar kepada persamaan volume, data-data yang menunjang pada perhitungan cadangan hidrokarbon adalah porositas dan saturasi hidrokarbon. Persamaan yang digunakan dalam metode volumetrik adalah sebagai berikut:

$$
\mathrm{G}=\frac{43560 . \text { Vbulk. NTG. } \phi \cdot(1-\mathrm{Sw})}{\text { Bgi Factor }}
$$

\section{METODOLOGI PENELITIAN}

Secara garis besar, penelitian ini mencakup 3 pokok bahasan penting, yaitu analisis petrofisika, analisis mudlog/core, dan perhitungan cadangan. Berikut adalah diagram alir penelitian :

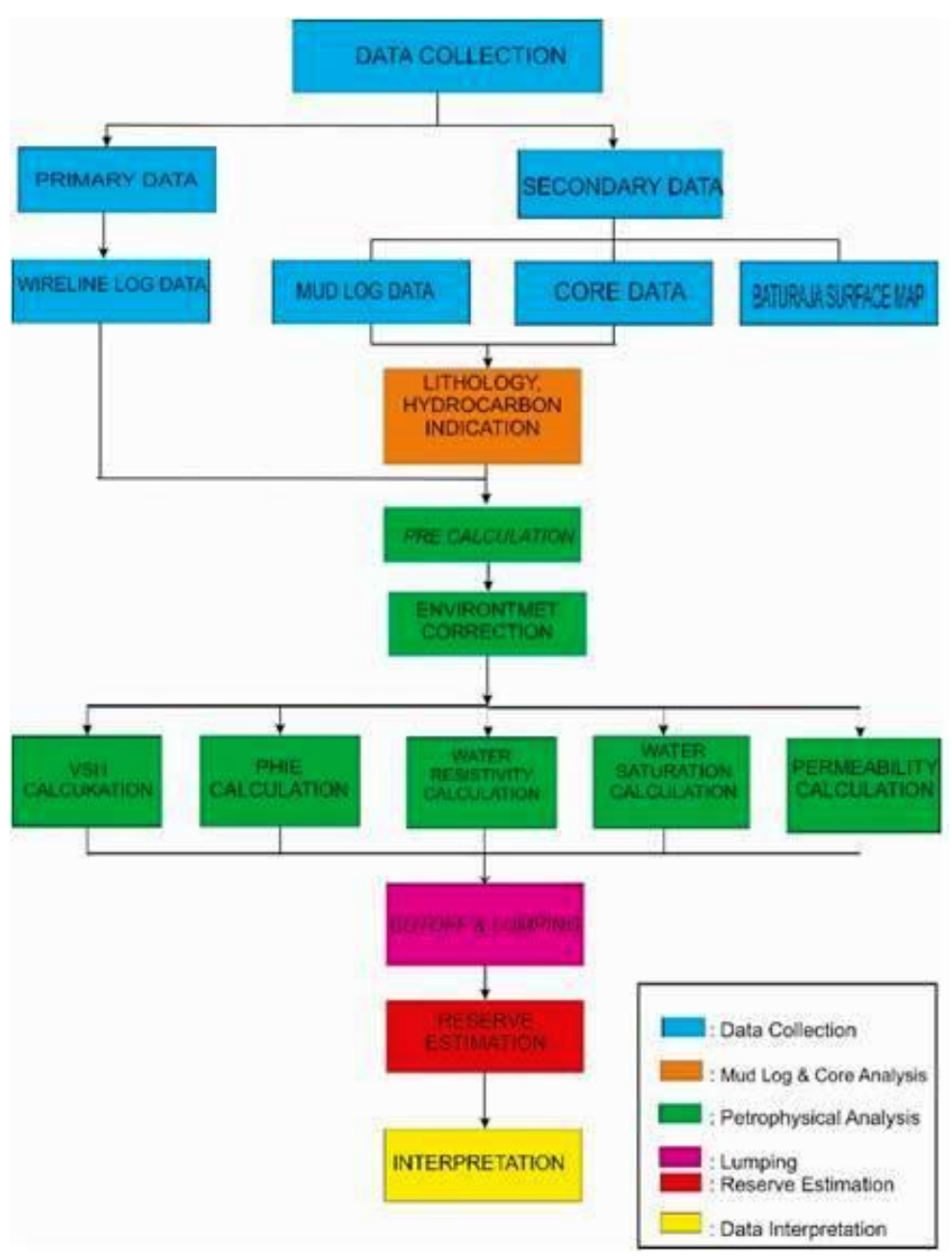

Gambar 1. Diagram Alir Penelitian. 
HASIL DAN PEMBAHASAN

\section{A. Porositas Keempat Sumur}

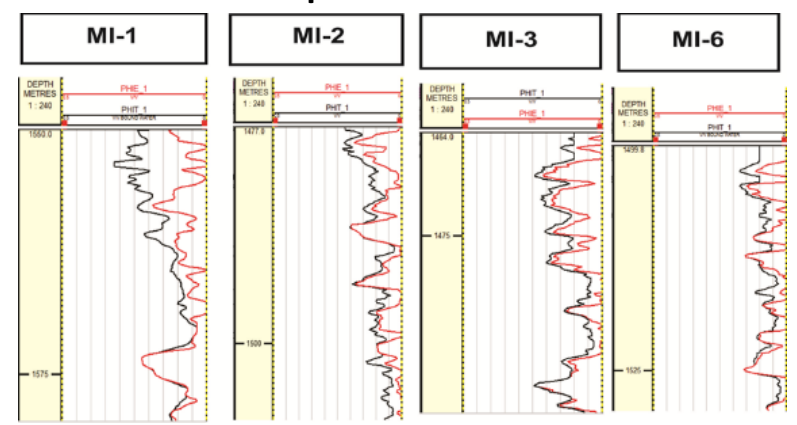

Gambar 2. Tampilan Porositas Keempat Sumur.

\section{B. Saturasi Air Keempat Sumur}

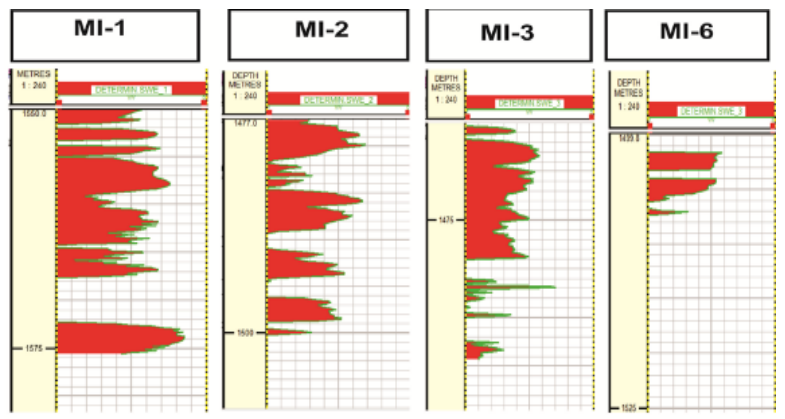

Gambar 3. Saturasi Air Keempat Sumur.

\section{Permeabilitas Keempat Sumur}

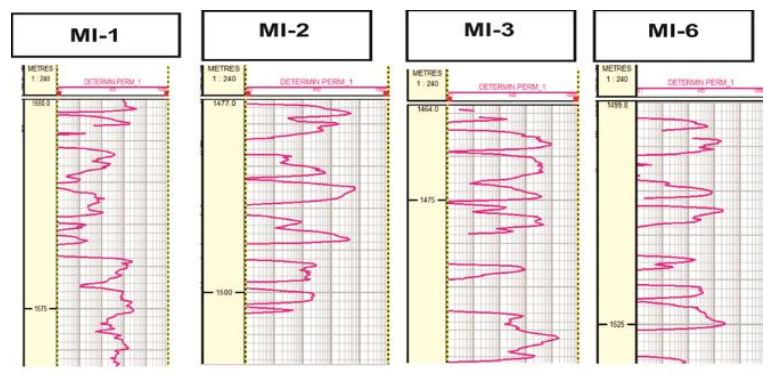

Gambar 4. Permeabilitas Keempat Sumur.

\section{Lumping}

Reservoar yang merupakan zona interest harus memiliki nilai porositas tinggi dan lapisan batuannya permeabel. Zona tersebut harus memiliki kandungan serpih yang sedikit, karena kandungan serpih yang banyak dapat menyebabkan reservoar menjadi kurang produktif. Dalam melakukan lumping, perlu ditetapkan nilai penggal (cut-off) yang berfungsi sebagai filter untuk mendapatkan zona reservoar bersih.

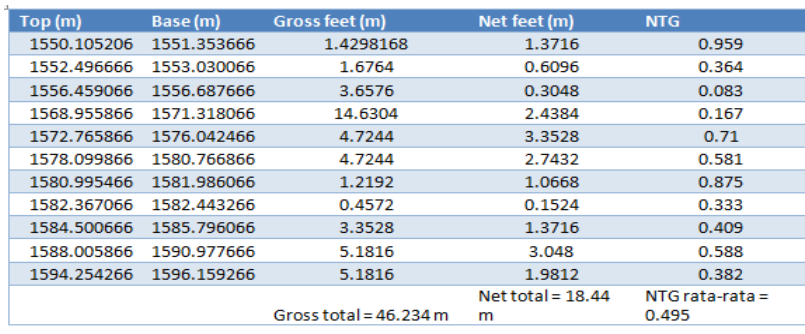

Gambar 5. Hasil Pembungkalan Sumur MI-1.

\begin{tabular}{|rcccc|}
\hline Top $(\mathrm{m})$ & Base $(\mathrm{m})$ & Gross Feet $(\mathrm{m})$ & Net Feet $(\mathrm{m})$ & \multicolumn{1}{c|}{ NTG } \\
\hline 1467.231 & 1469.136 & 5.21208 & 1.9812 & 0.380116959 \\
\hline 1469.8218 & 1472.336 & 3.2004 & 2.5908 & 0.80952381 \\
\hline 1473.6318 & 1474.927 & 2.5908 & 1.3716 & 0.529411765 \\
\hline 1476.6798 & 1478.128 & 3.2004 & 1.524 & 0.476190476 \\
\hline 1482.6234 & 1483.157 & 5.0292 & 0.6096 & 0.121212121 \\
\hline 1488.1098 & 1488.643 & 5.4864 & 0.6096 & 0.111111111 \\
\hline 1489.4814 & 1492.301 & 3.6576 & 2.8956 & 0.791666667 \\
\hline 1492.6818 & 1493.215 & 0.9144 & 0.6096 & 0.666666667 \\
\hline & & Gross Total $(\mathrm{m})=$ & Net Total $(\mathrm{m})=$ & \multicolumn{2}{l|}{ NTG rata-rata $=$} \\
\hline
\end{tabular}

Gambar 6. Hasil Pembungkalan Sumur MI-2.

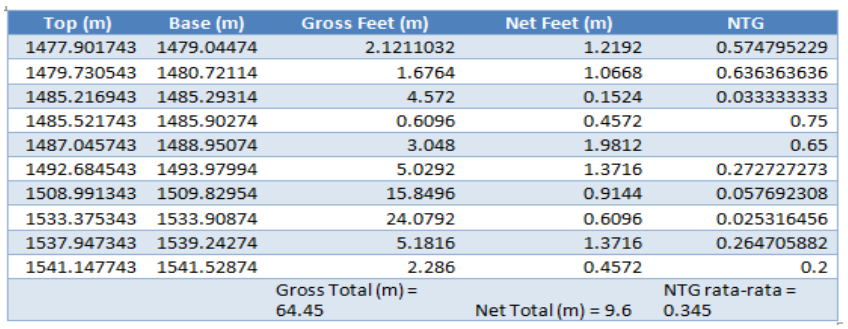

Gambar 7. Hasil Pembungkalan Sumur MI-3.

\begin{tabular}{|ccccc|}
\hline Top $(\mathrm{m})$ & Base $(\mathrm{m})$ & Gross Feet $(\mathrm{m})$ & Net feet $(\mathrm{m})$ & NTG \\
\hline 1504.124906 & 1504.95 & 5.2248816 & 0.9000744 & 0.172 \\
\hline 1505.174942 & 1505.399885 & 0.4498848 & 0.2999232 & 0.667 \\
\hline 1509.67501 & 1510.500103 & 5.0999136 & 0.9000744 & 0.176 \\
\hline 1511.775082 & 1512.59987 & 2.100072 & 0.9000744 & 0.429 \\
\hline 1523.625096 & 1525.349959 & 12.7500888 & 1.8001488 & 0.141 \\
\hline 1534.425074 & 1536.299899 & 10.94994 & 1.9501104 & 0.178 \\
\hline 1541.024909 & 1541.550079 & 5.2498752 & 0.6001512 & 0.114 \\
\hline & & & NTG rata-rata $=$ \\
& & & & \\
\end{tabular}

Gambar 8. Hasil Pembungkalan Sumur MI-6.

\section{E. Perhitungan Cadangan}

Perhitungan cadangan hidrokarbon menggunakan metode volumetrik, yaitu memperkirakan OGIP (Original Gas In Place). Berdasarkan model geologi yang secara geometrik menggambarkan volume hidrokarbon dalam reservoar. Dalam perhitungan cadangan gas alam, terdapat beberapa parameter yang harus diketahui, di antaranya adalah porositas, saturasi air, Volume bulk, dan Bgi factor. Nilai Bgi diasumsikan pada formasi Baturaja dan wilayah 
Prabimulih sebesar 0.0076. NTG ditentukan berdasarkan cut-off porositas, permeabilitas dan saturasi air. Cut-off permeabilitas diasumsikan gas mengalir di atas satu Milidarcy. Nilai penggal (Cutoff) dari saturasi air diasumsikan 0.5 untuk gas.

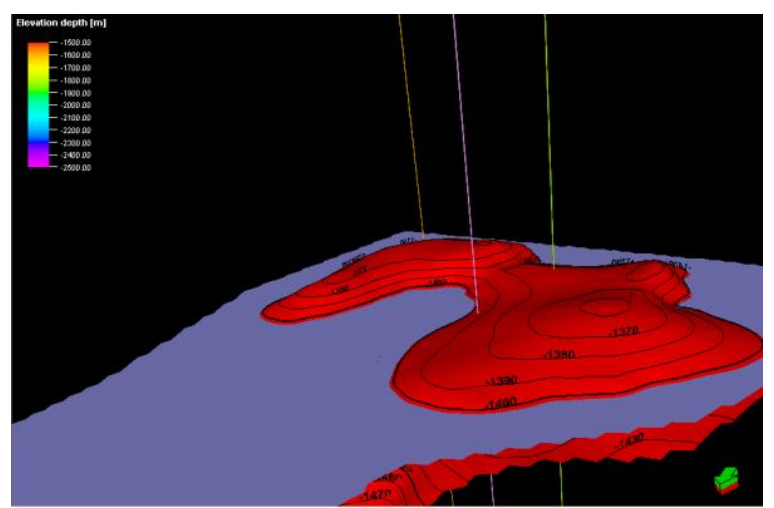

Gambar 9. Peta Surface Kompartemen Selatan.

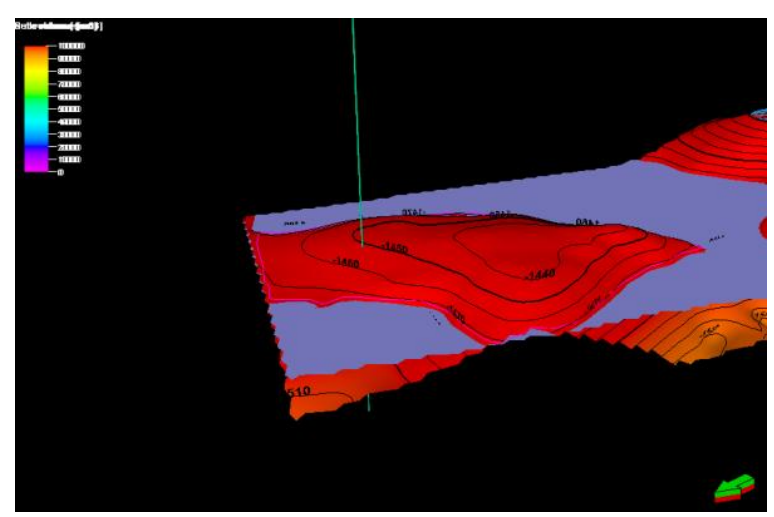

Gambar 10. Peta Surface Kompartemen Utara.

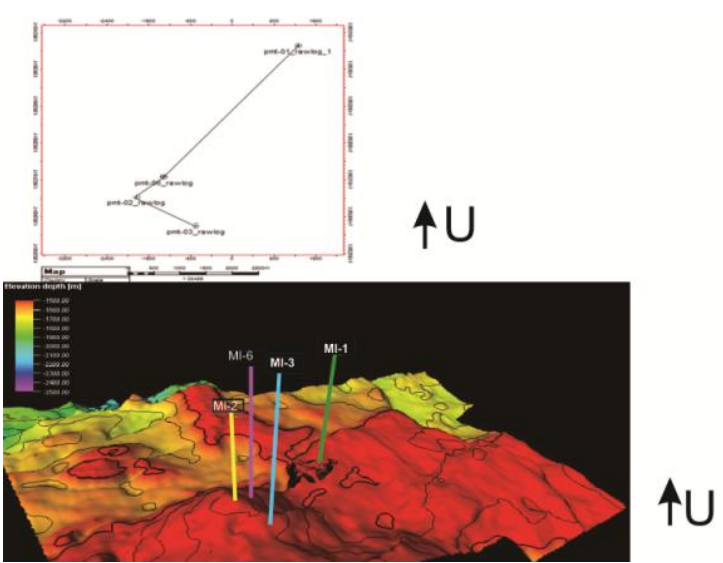

Gambar 11. Basemap Sumur dan Peta Top Surface.

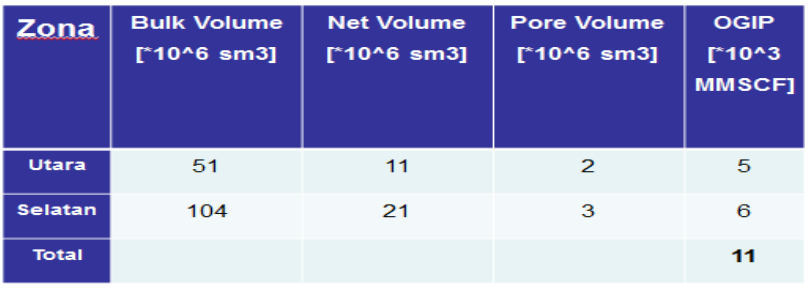

Gambar 12. Hasil Perhitungan Cadangan.

\section{KESIMPULAN}

Dari penelitian yang dilakukan, dapat ditarik beberapa buah kesimpulan sebagai berikut :

1. Formasi Baturaja Cekungan Sumatera Selatan telah terbukti melalui analisis petrofisika dan perhitungan cadangan memiliki hidrokarbon dengan jenis gas alam dalam jumlah yang melimpah.

2. Penentuan zona hidrokarbon dilakukan melalui analisis data mud log (gas reading, oil show, litologi), wireline log, sidewall core, dan data batuan inti (core).

3. Berdasarkan analisis petrofisika dan pembungkalan (lumping), diketahui bahwa sumur yang memiliki potensi keterdapatan hidrokarbon yang paling baik adalah sumur MI1.

4. Wilayah Kompartemen Utara yang dilewati oleh sumur MI-1 memiliki Original Gas in Place (OGIP) sebesar $5 \mathrm{BSCF}$, wilayah Kompartemen Selatan yang dilewati oleh sumur MI-2, MI-3, dan MI-6 juga memiliki Original Gas in Place (OGIP) yang sama, yaitus ebesar 6 BSCF.

\section{Ucapan Terima Kasih}

Penulis mengucapkan terima kasih kepada PT Pertamina Upstream Technology Center atas izin yang diberikan untuk mempublikasikan tulisan ini. Serta Ibu Anik, Pak Widya, dan Pak Fahyani selaku pembimbing dalam menyusun tulisan ini. 


\section{DAFTAR PUSTAKA}

Bateman, Richard M., 1985. Open-Hole Log Analysis and Formation Evaluation. International Human Resources Development Corporation. Boston.

Bishop, Michele G., 2000. South Sumatra Basin Province, Indonesia: The Lahat/TalangAkar-Cenozoic Total Petroleum System. USGS.

Darling, Toby, 2005. Well Logging and Formation Evaluation. Oxford: Elsevier Publishing Company.

Koesumadinata R.P., 1980. Geologi Minyak dan Gas Bumi. Edisi-2. Jilid 1 dan 2. Bandung: ITB.

Rider, Malcolm., 1996, The Geological Interpertation of Well Logs. Caithness, Scotland. 